\title{
BONE APPOSITION TO A TITANIUM-ZIRCONIUM ALLOY IMPLANT, AS COMPARED TO TWO OTHER TITANIUM-CONTAINING IMPLANTS
}

\author{
N. Saulacic ${ }^{1,2, \S}$, D.D. Bosshardt ${ }^{3, \S}$, M.M. Bornstein ${ }^{1}$, S. Berner ${ }^{4}$ and D. Buser ${ }^{1, *}$ \\ ${ }^{1}$ Department of Oral Surgery and Stomatology, School of Dental Medicine, University of Bern, Switzerland \\ ${ }^{2}$ Department of Cranio-Maxillofacial Surgery, University Hospital, Bern, Switzerland \\ ${ }^{3}$ Robert K. Schenk Laboratory of Oral Histology, School of Dental Medicine, University of Bern, Switzerland \\ ${ }^{4}$ Institut Straumann AG, Basel, Switzerland
}

${ }^{\S}$ Both authors contributed equally to the manuscript

\begin{abstract}
Implants made of commercially pure titanium (cpTi) are widely and successfully used in dentistry. For certain indications, diameter-reduced Ti alloy implants with improved mechanical strength are highly desirable. The aim was to compare the osseointegration of titanium-zirconium (TiZr) and cpTi implants with a modified sandblasted and acid-etched (SLActive) surface and with a Ti6Al4V alloy that was sand-blasted and acid-washed. Cylindrical implants with two, $0.75 \mathrm{~mm}$ deep, circumferential grooves were placed in the maxilla of miniature pigs and allowed to heal for 1, 2, 4 and 8 weeks. Undecalcified toluidine blue-stained ground sections were produced. Surface topography, area fraction of tissue components, and bone-to-implant contact (BIC) were determined. All materials showed significantly different surface roughness parameters. The amount of new bone within the implant grooves increased over time, without significant differences between materials. However, $\mathrm{BIC}$ values were significantly related to the implant material and the healing period. For TiZr and cpTi implants, the BIC increased over time, reaching values of $59.38 \%$ and 76.15 $\%$ after 2 weeks, and $74.50 \%$ and $84.67 \%$ after 8 weeks, respectively. In contrast, the BIC for Ti6Al4V implants peaked with $42.29 \%$ after 2 weeks followed by a decline to $28.60 \%$ at 8 weeks. Significantly more surface was covered by multinucleated giant cells on Ti6Al4V implants after 4 and 8 weeks. In conclusion, TiZr and cpTi implants showed faster osseointegration than Ti6Al4V implants. Both chemistry and surface topography might have influenced the results. The use of diameter-reduced TiZr implants in more challenging clinical situations warrants further documentation in long-term clinical studies.
\end{abstract}

Keywords: Osseointegration, dental implant, titaniumzirconium alloy, histology, histomorphometry

*Address for correspondence:

Daniel Buser

Department of Oral Surgery and Stomatology

School of Dental Medicine, University of Bern

Freiburgstrasse 7, CH-3010, Bern, Switzerland

Telephone Number: +4131632 2555

FAX Number: +41 31632 2566,

E-mail: daniel.buser@zmk.unibe.ch

\section{Introduction}

In the last two decades, the surface topography of implants, mainly consisting of commercially pure titanium (cpTi), has been thoroughly investigated and markedly improved (Buser et al., 1998; Gotfredsen et al., 2000; Sul et al., 2002). Today, microrough cpTi implants dominate the market (Wennerberg and Albrektsson, 2010), being produced with various techniques, such as sandblasting, acid-etching or combinations thereof. Significant enhancement of bone-to-implant contact (BIC) was found when the initial sand-blasted and acidetched cpTi surface (SLA) was made hydrophilic by chemical modification (SLActive) (Buser et al., 2004). The SLActive cpTi surface is produced with the same sand-blasting and acid-etching procedure as for SLA, but rinsed under $\mathrm{N}_{2}$ protection and continuously stored in a $\mathrm{NaCl}$ solution (Steinemann and Simpson, 2004). However, placement of dental implants may be restricted by a lack of sufficient bone volume at the implant site, requiring local bone augmentation. The utilisation of implants with a reduced diameter might avoid the necessity of local bone augmentation procedures. In comparison to the initial experiences with Ti grade 1, most of the implant systems today are made of much stronger Ti grade 4. Still, the mechanical properties of reduced-diameter grade 4 Ti implants to withstand strong masticatory forces are diminished compared to standard-diameter implants (Rangert et al., 1995; Zinsli et al., 2004).

In order to enhance its strength, Ti can be alloyed with other elements, such as aluminium (Al) and vanadium (V). About one third of all hip and knee replacements are successfully performed with Ti6Al4V, as demonstrated in a long-term study (Johnsen et al., 2006). Ti6Al4V alloy implants have not been recommended for cemented total hip arthroplasties, but are safe for anchorage without cement (Willert et al., 1996; Hinrichs et al., 2003). Since the early 1980s, the Ti6Al4V alloy has evolved to meet the needs in implant dentistry. Unfavourable results have been reported in dental applications, but they were mainly ascribed to the implant hollow screw design and unfavourable surface roughness (Malmqvist and Sennerby, 1990). More recently, high survival and success rates for dental implants made of Ti6Al4V have been reported (De Leonardis et al., 1999; Bratu et al., 2009). Some experimental studies indicated significantly reduced removal torque values of $\mathrm{Ti} 6 \mathrm{Al} 14 \mathrm{~V}$ when compared to 
cpTi implants and less favourable bone response (Han et al., 1998; Johansson et al., 1998), whereas others did not indicate any significant differences in bone response to both implant materials (Johansson et al., 1993).

Ti alloys containing zirconium $(\mathrm{Zr})$ show better tensile and fatigue strength than cpTi (Kobayashi et al., 1995; Ho et al., 2008). A titanium-zirconium (TiZr) alloy has recently been developed consisting of Ti alloyed with $13-15 \%$ Zr. The new binary material has a monophasic $\alpha$-structure which shows $13-42 \%$ higher endurance level than cpTi, with the highest difference for $3.3 \mathrm{~mm}$ tissue level implants (Bernhard et al., 2009). Although the same surface modifications using sandblasting and acid-etching can be applied to cpTi (SLActive) and TiZr (SLActive) implants, it is possible that these two implant materials may end up with different surface characteristics (e.g., roughness, hydrophilicity and wettability). The physicochemical surface characteristics of Ti (SLActive) and TiZr (SLActive) implants might thus elicit different tissue responses. No significant differences in BIC were found on Ti (SLActive) and TiZr (SLActive) within the grooves of cylindrical implants after 4 weeks of healing in miniature pigs (Gottlow et al., 2010) nor on standard screw-type Ti (SLActive) and TiZr (SLActive) dental implants after 2, 4 and 8 weeks of healing in dogs (Thoma et al., 2011).

The purpose of the present study was to examine the sequential healing and bone apposition to TiZr (SLActive) implants with a chemically modified, hydrophilic implant surface up to 8 weeks in a standardised and demanding implant model with circumferential grooves (Buser et al., 2004; Germanier et al., 2006). A chemically modified, sandblasted and acid-etched Ti implant (SLActive) and another alloy, Ti6Al4V implant, with a sandblasted and acid-washed surface served as controls.

\section{Materials and Methods}

\section{Implant design and surface characteristics}

All experimental implants were cylindrical and had a length of $6 \mathrm{~mm}$, a core diameter of $2.7 \mathrm{~mm}$, and 3 rings with an outer diameter of $4.2 \mathrm{~mm}$ (Buser et al., 2004; Germanier et al., 2006). The two circumferential grooves had a depth of $0.75 \mathrm{~mm}$ and a height of $1.8 \mathrm{~mm}$. The test and control implants were identical in shape, but differed in biomaterial composition and implant surface characteristics:

1. Test implant: TiZr implant with a $15 \%$ zirconium content ( $\alpha$-structure) and a sandblasted and acidetched chemically modified, hydrophilic surface (SLActive).

2. Control implant 1: Ti implant made of commercially pure titanium (cpTi) (grade 4) with a sandblasted and acid-etched chemically modified, hydrophilic surface (SLActive).

3. Control implant 2: Ti6Al4V implant with a sand-blasted and acid-washed surface.

The test and control 1 implants had a standard SLActive surface sandblasted (corundum) with large grits measuring 250-500 $\mu \mathrm{m}$ and then acid-etched in a boiling mixture

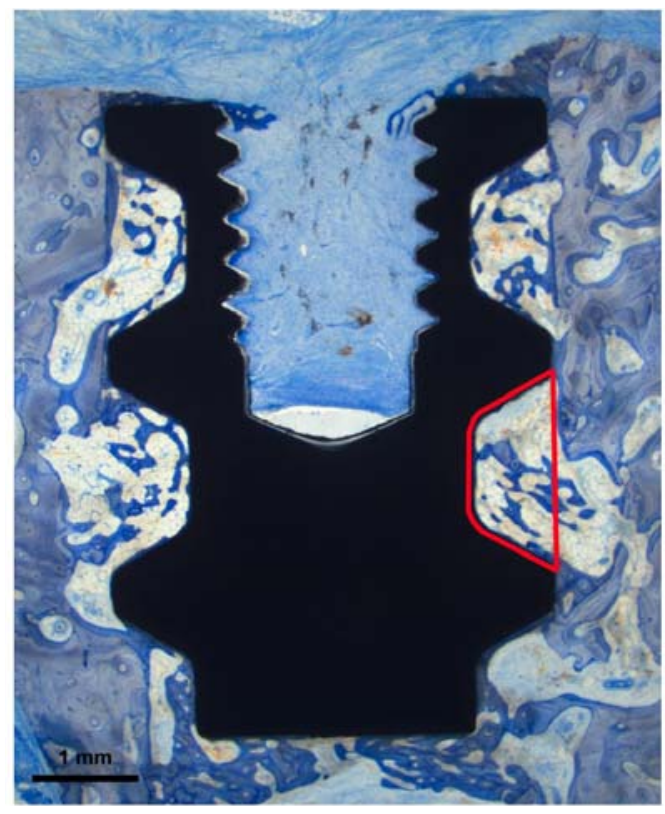

Fig. 1. Longitudinal ground section showing the implant, peri-implant tissues, and the four implant grooves with marked region of interest.

of $\mathrm{HCl}$ and $\mathrm{H}_{2} \mathrm{SO}_{4}$. After acid-etching, the implants were further treated under nitrogen cover gas in order to prevent exposure to air. The implants were rinsed with pure water and finally stored in isotonic saline solution (Steinemann and Simpson, 2004). Although the surface of the test implant material was treated the same way as the control implant material 1 , the characteristics of the two surfaces may differ because of the different materials used. The surface of the Ti6Al4V implants (control 2) was sandblasted in an identical way as the two other implant materials, followed by acid-washing ( $\mathrm{HNO}_{3} 65$ $\%$ ) and water rinsing. Following surface treatment, all three implant materials were gamma sterilised. Surface topographies were qualitatively examined and compared on prefabricated discs of $5 \mathrm{~mm}$ in diameter made of the same material and surface treatment as test, control 1 and control 2 implant materials using scanning electron microscopy (SEM). Surface topography was measured using confocal 3D white light microscopy ( $\mu$ Surf, NanoFocus AG, Oberhausen, Germany) over an area of $798 \mu \mathrm{m}$ x $798 \mu \mathrm{m}$. Three-dimensional roughness parameters $\mathrm{S}_{\mathrm{a}}$ (arithmetic mean deviation of the surface), $S_{t}$ (maximum peak-tovalley height of the surface), $S_{\text {sk }}$ (skewness of the surface) and a hybrid parameter Sdr (developed surface area) were calculated using a moving average Gaussian filter with a cut-off wavelength of $30 \mu \mathrm{m}$. Three measurements per sample and 3 samples per group were obtained $(n=9$ measurements).

\section{Study design}

A total of 12 adult (2-year-old) miniature female pigs were used in this study. The animals received standard food and water ad libitum. The protocol of the study was approved by the Committee for Animal Research, State of Bern, Switzerland (Approval No. 46/09), using a study design that has been successfully utilised in previous studies (Buser et al., 2004; Germanier et al., 2006). 
Animals were premedicated using ketamine (i.m. $20 \mathrm{mg} / \mathrm{kg}$ ), xylazine (i.m. $2 \mathrm{mg} / \mathrm{kg}$ ), atropine (i.v. 0.05 $\mathrm{mg} / \mathrm{kg}$ ) and midazolam (i.v. $0.5 \mathrm{mg} / \mathrm{kg}$ ) to achieve the intubation status. Inhalation anaesthesia was performed with isoflurane (1.0-15\%). Fentanyl patches $(5-10 \mathrm{mcg} / \mathrm{kg})$ were used for the intraoperative analgesia and the animals received antibiotic prophylaxis for three days (Duplocillin LA, 12000 U.I./kg).

The anterior region of the maxilla was chosen according to our previous experience (Buser et al., 2004; Germanier et al., 2006), allowing a simpler tooth extraction in comparison to the posterior maxilla. In total, three surgical interventions were performed per animal. In the first surgery, all six incisors in the maxilla were removed and the sites were allowed to heal for at least 3 months. Implants were placed during the second and third surgical interventions according to a split-mouth design. One implant per group (test, control 1 and control 2) was placed in one side of the maxilla using a systematic random protocol. In 6 animals, 3 to 4 implants were placed on the left side of the maxilla and one week later also on the right side of the maxilla. The animals were sacrificed one week later, yielding healing periods of 1 and 2 weeks. In the other 6 animals, 3 to 4 implants were placed on the left side of the maxilla and 4 weeks later also on the right side. The animals were sacrificed after 4 weeks, yielding healing periods of 4 and 8 weeks. A sample size consisted of 6 implants per experimental group and per time period (12 animals; $n=72$ in total; $n=18$ per time period; $n=6$ for each implant material). One bone block was harvested per side for each animal and the specimens chemically fixed in $4 \%$ formaldehyde solution supplemented with $\mathrm{CaCl}_{2}$.

\section{Histological preparation and analysis}

The specimens were rinsed in running tap water, dehydrated in ascending concentrations of alcohol, and embedded in methylmethacrylate (Schenk, 1984), as previously described (Buser et al., 1991; Cochran et al., 1998). Each implant was sectioned parallel to its longitudinal axis in the vestibulo-oral direction, resulting in three undecalcified sections of about $500 \mu \mathrm{m}$ thickness. The sections were ground to a final thickness of $80 \mu \mathrm{m}$, superficially stained with toluidine blue (Schenk, 1984) and the two central-most sections were used for descriptive and morphometric analyses. The bone-to-implant contact (BIC) was determined for new bone matrix (osteoid, mineralised bone matrix) deposited along the surface of the implant grooves. The percentage of BIC was determined directly in the light microscope by intersection counting, using an integrative eyepiece with parallel sampling lines at a magnification of $\mathrm{x} 250$ using a square grid (distance between test points $=40 \mu \mathrm{m}$ at a magnification of $\mathrm{x} 250$ ) (Weibel, 1979). In addition, the area fractions of soft tissue, osteoid and new mineralised bone within the area of the well-defined implant grooves were assessed by counting intersections using the same grid and magnification. Osteoid is the organic nonmineralised matrix of bone consisting of collagen and noncollagenous proteins. Osteoid in lamellar bone forms a thin matrix seam that is homogeneously eosinophilic and interposed between osteoblasts and mineralised bone matrix. Such a clear-cut distinction between mineralised bone matrix and osteoid cannot be made for woven bone. However, also during woven bone formation an equivalent to osteoid exists. Due to the structural nature of woven bone, the osteoid consists of thick randomly distributed collagen fibres, which intermingle with nearby osteoblasts. Importantly, the osteoid of woven bone can clearly be distinguished from the soft tissue, rich in blood vessels, that fills the more central portion of neighbouring struts of woven bone. The region of interest was defined by the surface of the implant groove and the extension of the outer implant diameter (Fig. 1). The presence of multinucleated giant cells (MNGCs) on the implant surface within the grooves was determined for each implant material. The percentage of implant surface confined to the groove covered by these cells was calculated.

\section{Statistical analysis}

A two-tailed Student $t$-test (unequal variance) was used to compare differences in $\mathrm{Sa}, \mathrm{St}, \mathrm{Ssk}$ and $\mathrm{Sdr}$ between three different implant materials.

The initial descriptive analysis of the data was done using scatter plots for the distribution of the analysed tissues (new osteoid, new mineralised bone, total new bone, and soft tissue) for BIC and bone volume (BV/TV) in the grooves analysed. To detect potential differences in the tissues for the three different implant materials tested for each time point, a Kruskal-Wallis test was performed for the BIC and BV/TV data sets separately. To analyse differences in the amount of hard and soft tissues over the four time points and the influence of the different implant materials, nonparametric analysis of variance (ANOVA) was used applying a Brunner-Langer model (Brunner et al., 2002).

For the group comparison of implant surface fractions covered by MNGCs, we have used analysis of variance with Tukey postprocessing (SAS ${ }^{\circledR}$ PROC GLM). The significance level chosen for all statistical tests was $p \leq$ 0.05 . Due to the small sample size and the explorative nature of this study, the $p$ values were not adjusted for multiple testing. Therefore, statistically significant findings should be interpreted as trends. The ANOVA analyses were performed using a licensed software package (SAS 9.1, SAS Institute, Cary, NC, USA).

\section{Results}

\section{Surface characterisation}

Morphological differences in surface topography are shown in Fig. 2. Quantitative topographical analysis demonstrated statistically significant differences between the three implant surfaces for all roughness parameters $(p<0.01)$, except for $\mathrm{S}_{\mathrm{a}}$ between TiZr (SLActive) and Ti6Al4V (Table 1).

\section{Histological and histomorphometric analysis}

For all implant materials, bony ingrowth into the implant grooves and direct bone-to-implant contact (BIC) were evident already at 1 week of healing (Tables 2 and 3, Figs. 3 and 4). While there was more osteoid than mineralised 
Table 1. Surface roughness parameters for the three implant types. Data are shown as means \pm SD.

\begin{tabular}{ccccc}
$\begin{array}{c}\text { Implant } \\
\text { type }\end{array}$ & $\begin{array}{c}\text { Arithmetic mean } \\
\text { deviation of the surface } \\
\text { (Sa, ìm) }\end{array}$ & $\begin{array}{c}\text { Maximum peak-to- } \\
\text { valley height of the } \\
\text { surface (St, ìm) }\end{array}$ & $\begin{array}{c}\text { Skewness of the } \\
\text { surface (Ssk) }\end{array}$ & $\begin{array}{c}\text { Developed surface } \\
\text { area (Sdr, \%) }\end{array}$ \\
\hline TiZr & $1.299 \pm 0.093$ & $8.90 \pm 0.36$ & $0.211 \pm 0.059$ & $39.0 \pm 3.3$ \\
cpTi & $1.002 \pm 0.020$ & $6.73 \pm 0.18$ & $0.142 \pm 0.032$ & $29.6 \pm 1.2$ \\
Ti6Al4V & $1.333 \pm 0.034$ & $9.49 \pm 0.23$ & $-0.073 \pm 0.031$ & $55.6 \pm 2.3$ \\
\hline
\end{tabular}

Table 2. Percentage of osteoid, mineralised bone, total new bone (osteoid and mineralised bone), and soft tissue over time in the area created by the implant grooves for the three implant materials. Data are shown as means \pm SD.

\begin{tabular}{cccccc}
$\begin{array}{c}\text { Time } \\
\text { point }\end{array}$ & $\begin{array}{c}\text { Implant } \\
\text { material }\end{array}$ & Osteoid & $\begin{array}{c}\text { Mineralised } \\
\text { bone }\end{array}$ & $\begin{array}{c}\text { Total new } \\
\text { bone }\end{array}$ & Soft tissue \\
\hline \multirow{2}{*}{ Week 1 } & TiZr & $11.73 \pm 3.87$ & $0.74 \pm 0.52$ & $12.48 \pm 4.39$ & $86.24 \pm 3.67$ \\
& cpTi & $14.17 \pm 5.74$ & $0.94 \pm 1.24$ & $15.11 \pm 6.98$ & $84.20 \pm 6.74$ \\
& Ti6Al4V & $15.10 \pm 3.79$ & $1.08 \pm 1.00$ & $16.17 \pm 4.78$ & $83.33 \pm 4.20$ \\
\hline \multirow{3}{*}{ Week 2 } & TiZr & $16.75 \pm 2.96$ & $20.47 \pm 3.33$ & $37.22 \pm 6.29$ & $60.64 \pm 3.95$ \\
& CpTi & $16.89 \pm 3.90$ & $23.08 \pm 3.52$ & $39.97 \pm 7.42$ & $58.72 \pm 4.86$ \\
& Ti6Al4V & $13.28 \pm 2.81$ & $18.14 \pm 6.71$ & $31.42 \pm 9.52$ & $66.12 \pm 8.00$ \\
\hline \multirow{2}{*}{ Week 4 } & TiZr & $16.49 \pm 6.47$ & $22.65 \pm 6.47$ & $39.14 \pm 6.47$ & $60.48 \pm 6.47$ \\
& cpTi & $14.61 \pm 3.66$ & $22.23 \pm 6.16$ & $36.84 \pm 9.82$ & $62.67 \pm 5.83$ \\
& Ti6Al4V & $17.17 \pm 6.47$ & $22.95 \pm 7.07$ & $40.11 \pm 13.53$ & $59.78 \pm 2.49$ \\
\hline \multirow{2}{*}{ Week 8 } & TiZr & $2.47 \pm 0.79$ & $38.58 \pm 7.31$ & $41.05 \pm 8.10$ & $58.37 \pm 8.53$ \\
& cpTi & $1.93 \pm 1.03$ & $35.80 \pm 9.59$ & $37.73 \pm 10.62$ & $61.98 \pm 9.85$ \\
\hline
\end{tabular}

Statistically significant differences are marked with the same letters (alpha level of 0.05).

Table 3. Percentage of osteoid, mineralised bone, total new bone (osteoid and mineralised bone), and soft tissue in contact with the surface along the grooves of the three implant materials over time. Data are shown as means $\pm \mathrm{SD}$.

\begin{tabular}{cccccc}
$\begin{array}{c}\text { Time } \\
\text { point }\end{array}$ & $\begin{array}{c}\text { Implant } \\
\text { type }\end{array}$ & Osteoid & Mineralised bone & Total new bone & Soft tissue \\
\hline \multirow{2}{*}{ Week 1 } & TiZr & $7.47 \pm 4.33$ & $1.72 \pm 2.77$ & $9.19 \pm 7.10$ & $90.46 \pm 6.74$ \\
& cpTi & $10.89 \pm 5.97$ & $2.73 \pm 4.47$ & $13.62 \pm 10.44$ & $86.26 \pm 10.64$ \\
& Ti6Al4V & $7.67 \pm 5.05$ & $1.47 \pm 3.16$ & $9.15 \pm 8.21$ & $90.14 \pm 8.34$ \\
\hline \multirow{2}{*}{ Week 2 } & TiZr & $21.85 \pm 6.84$ & $37.53 \pm 12.89$ & $59.38 \pm 19.73$ & $40.31 \pm 15.63$ \\
& cpTi & $14.01 \pm 5.31$ & $62.14 \pm 26.32$ & $76.15 \pm 31.62$ & $23.52 \pm 21.84$ \\
& Ti6Al4V & $16.61 \pm 10.70$ & $25.68 \pm 20.71$ & $42.29 \pm 31.41$ & $57.62 \pm 31.08$ \\
\hline \multirow{2}{*}{ Week 4 } & TiZr & $23.49 \pm 8.03 \mathrm{a}$ & $50.59 \pm 8.42 \mathrm{a}$ & $74.09 \pm 16.45 \mathrm{a}$ & $25.85 \pm 7.58 \mathrm{a}$ \\
& $\mathrm{cpTi}$ & $12.13 \pm 5.39$ & $63.35 \pm 12.30 \mathrm{~b}$ & $75.48 \pm 17.69 \mathrm{~b}$ & $24.53 \pm 15.19 \mathrm{~b}$ \\
& Ti6Al4V & $6.43 \pm 2.18 \mathrm{a}$ & $20.36 \pm 10.69 \mathrm{a}, \mathrm{b}$ & $26.79 \pm 12.87 \mathrm{a}, \mathrm{b}$ & $73.22 \pm 10.28 \mathrm{a}, \mathrm{b}$ \\
\hline \multirow{2}{*}{ Week 8 } & TiZr & $2.71 \pm 1.60$ & $71.80 \pm 9.01 \mathrm{a}$ & $74.50 \pm 10.61 \mathrm{a}$ & $25.48 \pm 8.78 \mathrm{a}$ \\
& $\mathrm{cpTi}$ & $1.48 \pm 1.74$ & $83.19 \pm 10.88 \mathrm{~b}$ & $84.67 \pm 12.62 \mathrm{~b}$ & $15.32 \pm 9.36 \mathrm{~b}$ \\
& Ti6Al4V & $2.20 \pm 1.35$ & $26.40 \pm 30.17 \mathrm{a}, \mathrm{b}$ & $28.60 \pm 31.52 \mathrm{a}, \mathrm{b}$ & $71.42 \pm 30.90 \mathrm{a}, \mathrm{b}$ \\
\hline
\end{tabular}

Statistically significant differences are marked with the same letters (alpha level of 0.05)

bone present within the implant grooves at 1 week, the fraction of total new bone and the ratio between mineralised bone and osteoid steadily increased over time within the implant grooves (Table 2, Figs. 3-8). While the mean area fraction of bone in the implant grooves increased over time for all implant materials (Fig. 9), no statistically significant differences were observed between implant materials (Table 4). Bone trabeculae first consisted entirely of woven bone (Figs. 3-5) and were later reinforced by parallel-fibered bone (Figs. 6-8). Mature bone marrow was not seen before week 8 (Figs. 3-8). Maturation of bone marrow adjacent to Ti6Al4V implants was less advanced than for TiZr (SLActive) and cpTi (SLActive) implants (Fig. 6). From week 4 to 8, many MNGCs were regularly observed on the surface of all Ti6Al4V implants (Figs. 6f and 8c). In contrast, almost no MNGCs were observed on TiZr (SLActive) or cpTi (SLActive) implants throughout the observation period (Figs. 8 and 

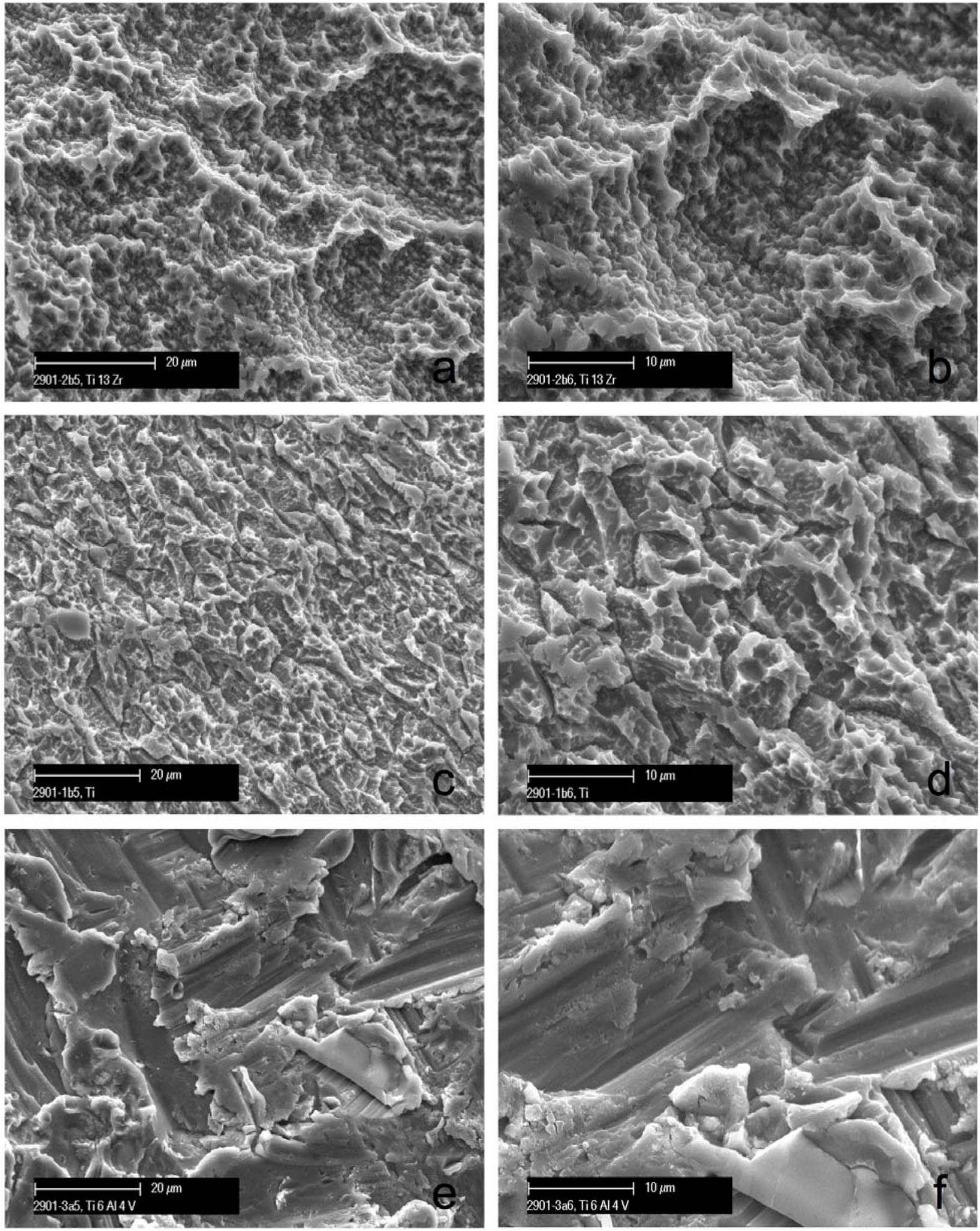

Fig. 2. Scanning electron microscope images showing the surface topographies of sandblasted and acid-etched (a, b) TiZr, (c, d) cpTi and sandblasted and acid-washed (e, f) Ti6Al4V surfaces.

10). The BIC steadily increased over time for both TiZr (SLActive) and cpTi (SLActive) implants, reaching values of $59.38 \%$ and $76.15 \%$ after 2 weeks, and $74.50 \%$ and $84.67 \%$ after 8 weeks (Table 3, Fig. 10), respectively. The most pronounced increase in BIC occurred between week 1 and week 2 . The development of the BIC on the Ti6Al4V surface showed a different pattern. After a peak of $42.29 \%$ at 2 weeks, the BIC dropped to $28.60 \%$ at 8 weeks (Table 3, Fig. 10). The detailed statistical analysis including significant differences for the BIC in relation to time, implant material and combined effect is shown in Table 5. The percentages of implant surface covered by MNGCs (mean, \pm standard error) were as follows for TiZr, cpTi, and Ti6Al4V, respectively: $0.28( \pm 0.21), 0.00$ 

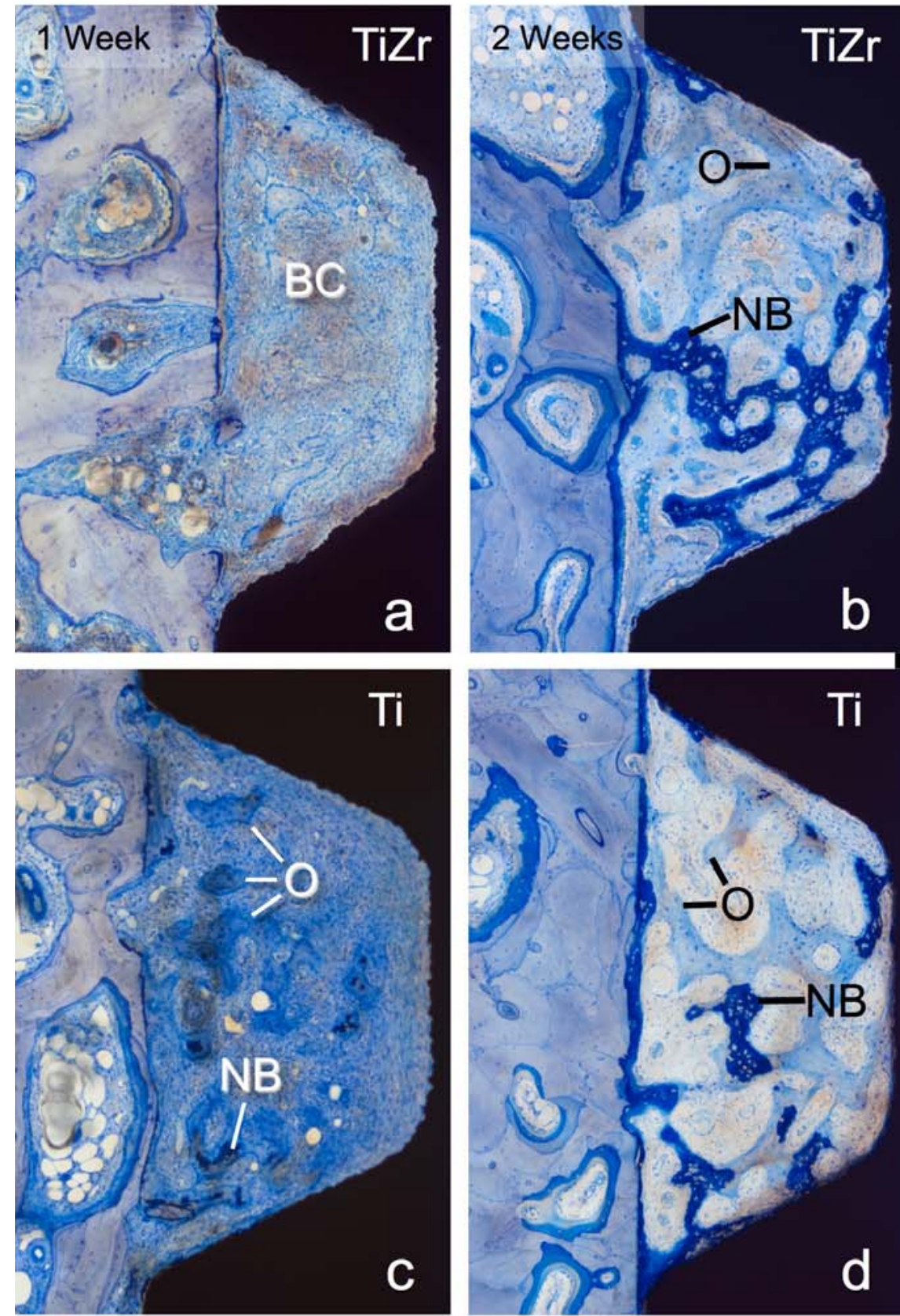

Fig. 3. Histological sections
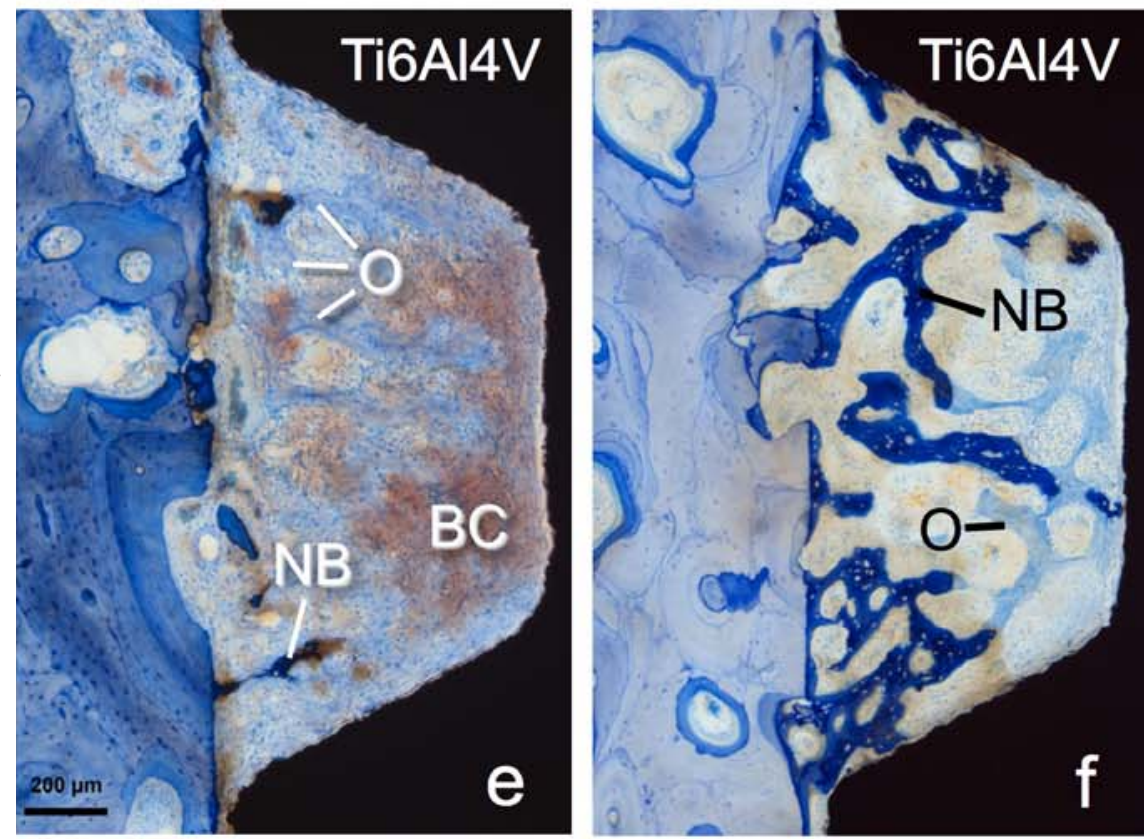
delineated by the implant surface and the bony wall of pristine bone at $1(\mathbf{a}, \mathbf{c}, \mathbf{e})$ and $2(\mathbf{b}, \mathbf{d}, \mathbf{f})$ weeks for all three implant materials. After 1 week, the blood coagulum (BC) is still present and most of the newly formed bone is osteoid (O). New mineralised bone (NB) is also present close to the cut bone, whereas little osteoid covers the implant surfaces. After 2 weeks, there is less blood coagulum, most of the newly formed bone matrix is mineralised, and the bone-toimplant contact has significantly increased from 1 to 2 weeks. 

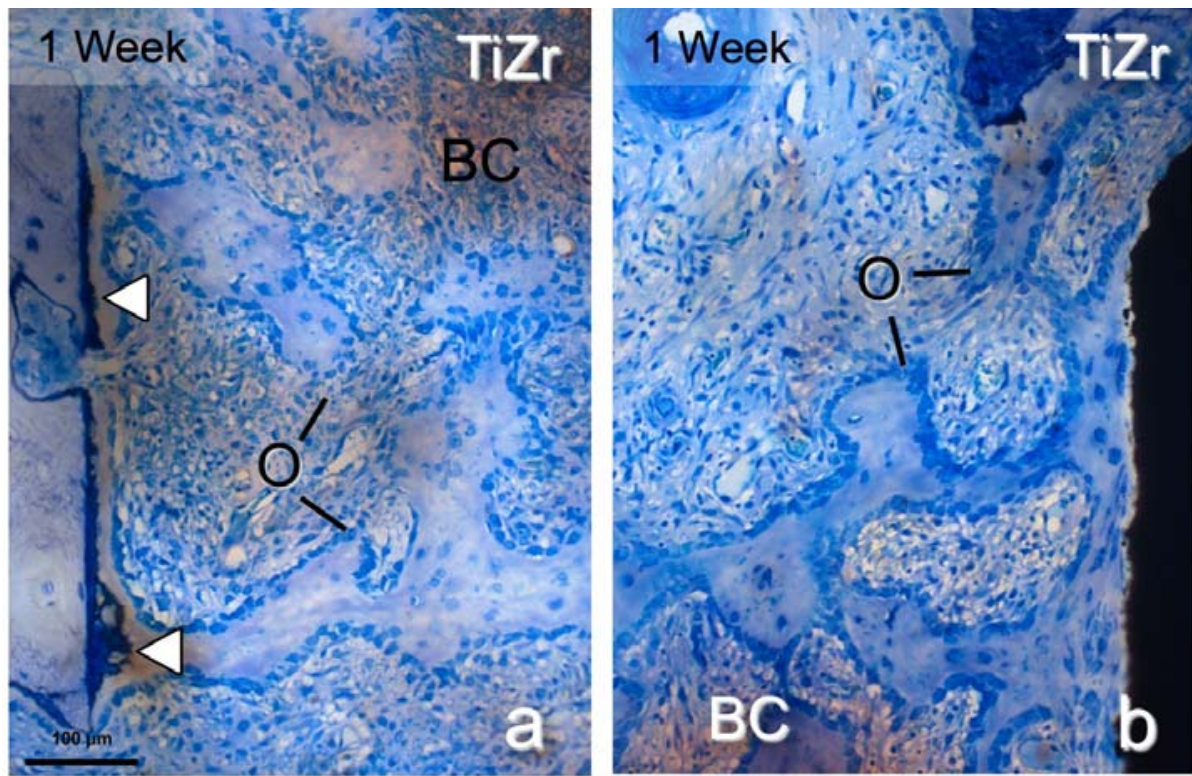

Fig. 4. Detailed histological
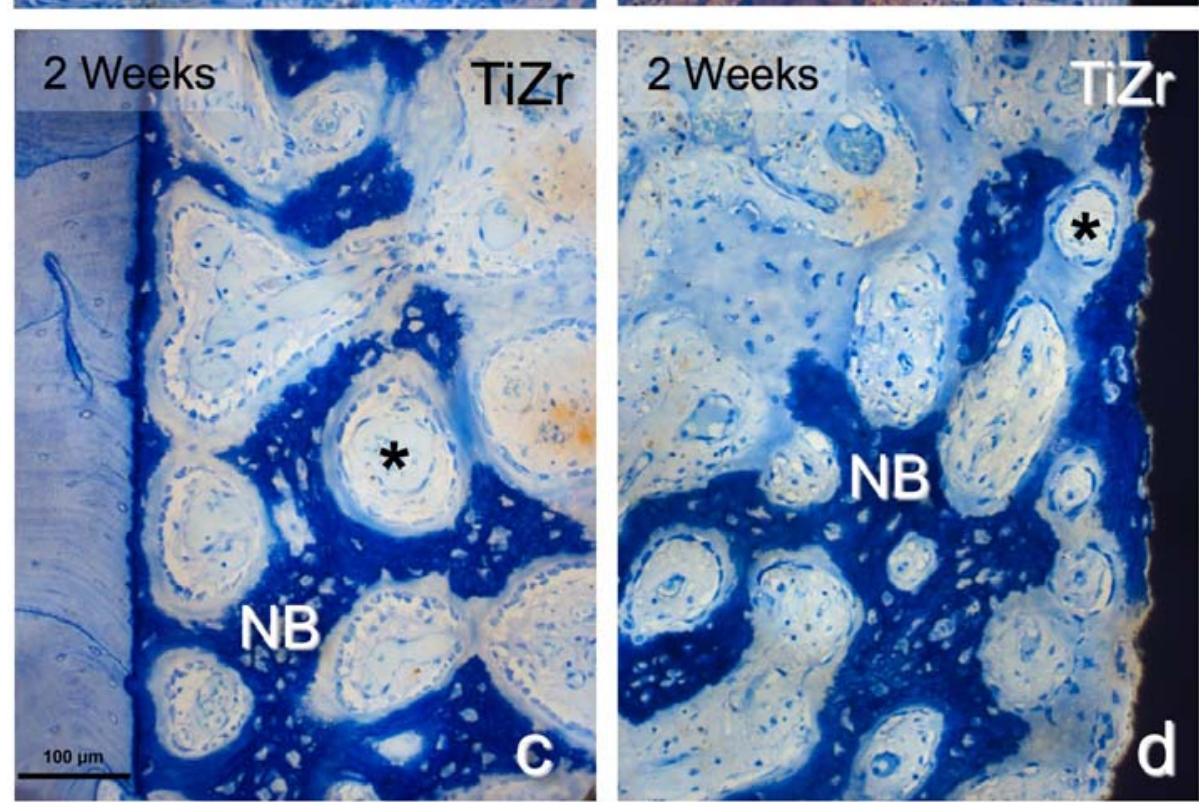

the cut bone $(\mathbf{a}, \mathbf{c})$ and facing the TiZr implants $(\mathbf{b}, \mathbf{d})$. At 1 week (a, b), the blood clot (BC) is clearly visible and osteoid (O) is seen connected to the cut old bone and deposited onto the implant surface. Arrowheads indicate initial mineralisation of osteoid. At 2 weeks (c, d), a dense network of trabecular bone is present, the ratio between mineralised bone (NB) and osteoid has increased, and developing primary osteons are seen $(*)$.

$( \pm 0.00), 2.26( \pm 1.50)$ after 1 week, $1.19( \pm 0.64), 3.23$ $( \pm 3.23), 12.11( \pm 5.18)$ after 2 weeks, $5.12( \pm 1.79), 3.38$ $( \pm 0.92), 42.61( \pm 3.78)$ after 4 weeks, and $3.19( \pm 0.77)$, $0.42( \pm 0.20), 54.37( \pm 12.17)$ after 8 weeks (Fig. 10). The values for Ti6Al4V after 4 and 8 weeks were significantly different from those obtained for TiZr and cpTi.

\section{Discussion}

The present experimental study examined the influence of the implant material on new bone formation using an implant model with circumferential grooves in miniature pigs. In contrast to the study of Gottlow et al. (2010), we examined the dynamics of bone healing by using four different healing periods. When compared with another animal study (Thoma et al., 2011), a much more demanding and better discriminating model has been used in the present study, since the implant grooves created a standardised defect gap of $750 \mu \mathrm{m}$. This defect gap is much larger than in the clinical situation. The present implant groove model is appropriate to study early bone healing events following implant placement, since the created defects are delineated on one side by the implant surface, and on the other side by the bony wall of the implant bed (Buser et al., 2004; Germanier et al., 2006).

TiZr alloy has been recently introduced in the field of implant dentistry for more challenging clinical situations, because it provides higher mechanical properties than cpTi grade 4 (Al-Nawas et al., 2011; Barter et al., 2011; Chiapasco et al., 2011). Nevertheless, Ti6A14V implants could also be used for small diameter dental implants because of improved mechanical strength when compared to cpTi and because of their favourable clinical documentation in orthopaedics (Bauer et al., 2009). All three implant surfaces used in the present study demonstrated moderate roughness values comparable to other contemporary implant systems (Wennerberg and Albrektsson, 2010). Concerning the amount of newly formed bone inside the implant grooves, no statistically significant differences were found between the three implant materials over time. The amount of new bone 
Fig. 5. Detailed histological views within the grooves at 2 weeks facing the cut bone (a) and facing the Ti6Al4V implants (b). A mineralised bone matrix (NB) is connected to the cut old bone and developing primary osteons are seen $(*)$. Osteoid $(\mathrm{O})$ is deposited onto the implant surface.

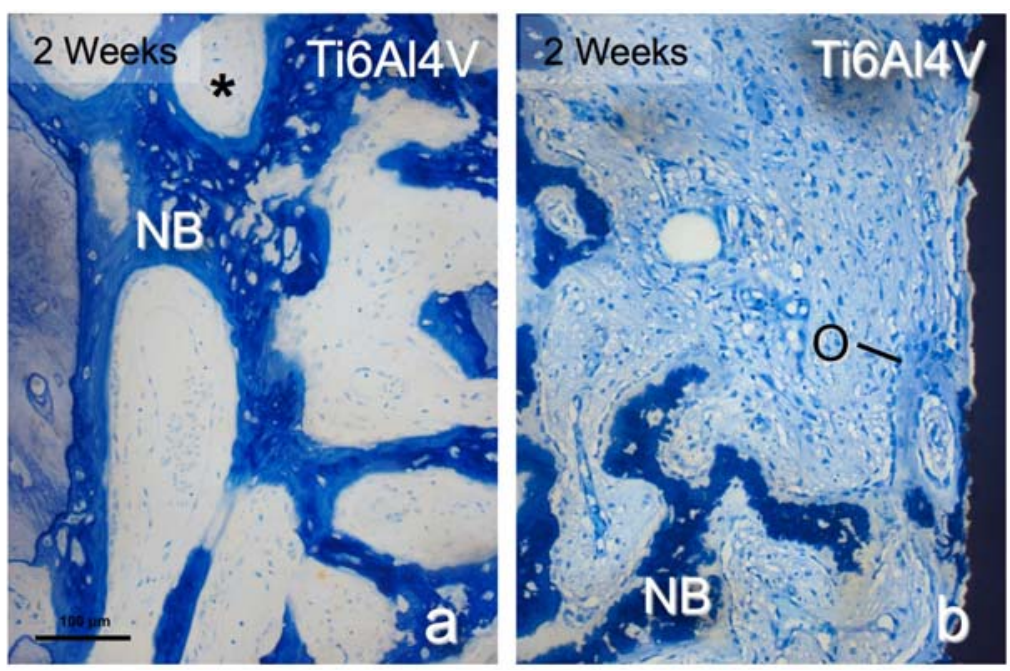

Table 4. Effect of time, implant material and combined effects (time and material) on the amount of osteoid, mineralised bone, total new bone, and soft tissue in the area created by the implant grooves for the three implant materials.

\begin{tabular}{ccccc} 
Effect & Osteoid & $\begin{array}{c}\text { Mineralised } \\
\text { bone }\end{array}$ & $\begin{array}{c}\text { Total new } \\
\text { bone }\end{array}$ & Soft tissue \\
\hline Time & $p=0.0002$ & $p<0.0001$ & $p<0.0001$ & $p<0.0001$ \\
Implant material & $p=0.9763$ & $p=0.9978$ & $p=0.9560$ & $p=0.9325$ \\
Combined & $p=0.2437$ & $p=0.1770$ & $p=0.4395$ & $p=0.4138$ \\
\hline
\end{tabular}

Table 5. Effect of time, implant material, and combined effects (time and material) on the amount of osteoid, mineralised bone, total new bone, and soft tissue deposited on the implant surface along the grooves of the three implant materials.

\begin{tabular}{ccccc} 
Effect & Osteoid & $\begin{array}{c}\text { Mineralised } \\
\text { bone }\end{array}$ & Total new bone & Soft tissue \\
\hline Time & $p=0.0003$ & $p<0.0001$ & $p=0.0009$ & $p=0.0008$ \\
Implant material & $p=0.0250$ & $p<0.0001$ & $p<0.0001$ & $p<0.0001$ \\
Combined & $p=0.0074$ & $p=0.2506$ & $p=0.6115$ & $p=0.5737$ \\
\hline
\end{tabular}

formed within the grooves was only time-dependent, indicating a good healing potential in this animal model. The apposition of new bone onto the surface of the three examined implant materials, however, showed statistically significant differences. Rather comparable values were found for the TiZr (SLActive) and cpTi (SLActive) implants. In contrast, the BIC values for Ti6A14V implants remained significantly lower from week 2 until the end of the observation period.

The alteration in surface chemistry (i.e., SLActive) as compared to the standard SLA surface resulted in significantly greater BIC at 2 and 4 weeks of healing in a miniature pig model (Buser et al., 2004) and recently at 4 weeks in a human model (Lang et al., 2011). The BIC values in the present study for cpTi (SLActive) implants at 2, 4 and 8 weeks corroborate previous findings (Buser et al., 2004; Gottlow et al., 2010). Increased oxygen on the hydrophilic titanium surface was attributed to the $\mathrm{TiO}_{2}$ layer and increased hydroxylated/hydrated groups bound to the implant surface (Textor et al., 2001). Increased surface wettability affects the adsorption of inorganic matter (Ca and $\mathrm{P}$ ) and molecules (proteins, lipoproteins and peptides) as well as the fibrin network from the blood onto the hydroxylated/hydrated groups of the SLActive surface, leading to a shortening of the healing period (Schwarz et al., 2009).

In the present study, the peak BIC values throughout the healing period showed some delay for TiZr (SLActive) implants in comparison to cpTi (SLActive) implants, without reaching statistical significance. It is presently not possible to know to which extent the material properties or the surface topography caused this slight difference. The surface of TiZr alloy is covered by a mixture of chemically inert $\mathrm{TiO}_{2}$ and $\mathrm{ZrO}_{2}$ (Chen et al., 2008). Due to its monophasic metal structure, TiZr can be treated like cpTi grade 4 . Although the same surface treatment was applied to TiZr (SLActive) and cpTi (SLActive) implants in the present study, significantly different surface roughness values were obtained. This implies that both surface roughness and surface chemistry may have caused the slight difference in the speed of bone apposition to the implant materials. The different biological profile between TiZr and cpTi may be influenced by surface properties such as roughness, surface energy and substrate composition 

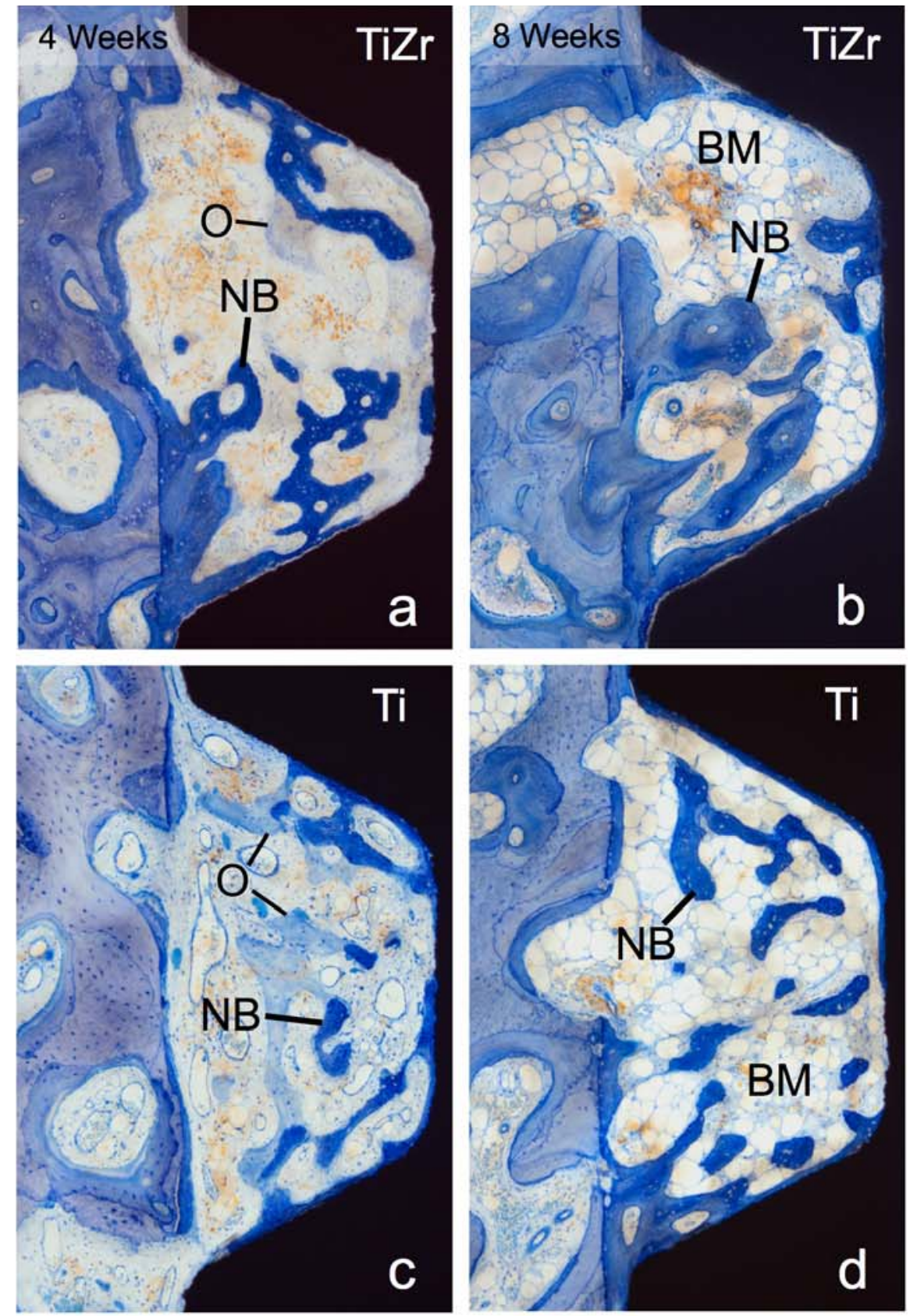

Fig. 6. Histological appearance within the implant grooves at 4 (a, c e) and $8(\mathbf{b}, \mathbf{d}, \mathbf{f})$ weeks for all three implant materials. The grooves of all three implant materials are filled with approximately the same amount of new bone (NB). Most of the newly formed bone matrix is mineralised and residual coagulum is still present. After 8 weeks, bone is much more mature, as indicated by an increased ratio of mineralised bone to osteoid (O) and a higher maturity of bone marrow (BM). The boneto-implant contact is high for the cpTi and TiZr implant materials. However, the Ti6Al4V implants reveal markedly reduced bone-toimplant contact, less mature bone marrow, and numerous MNGCs (arrows).
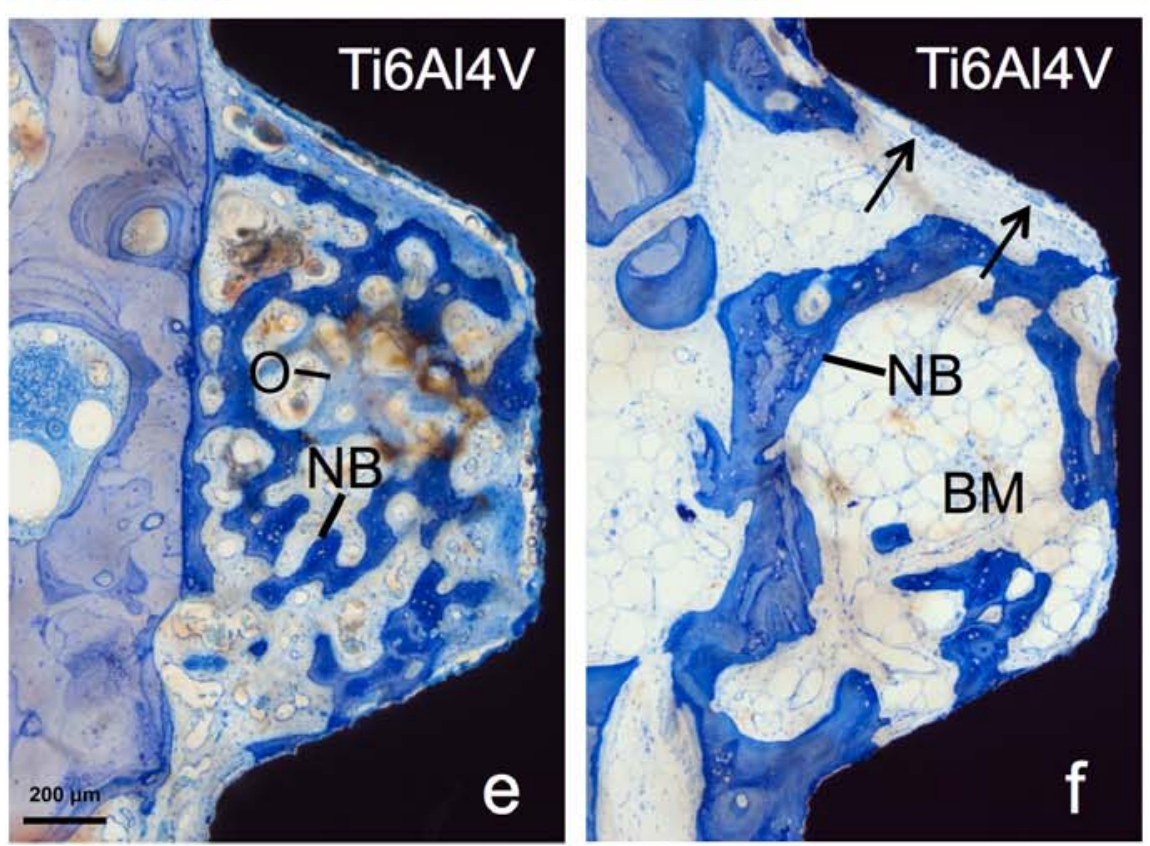

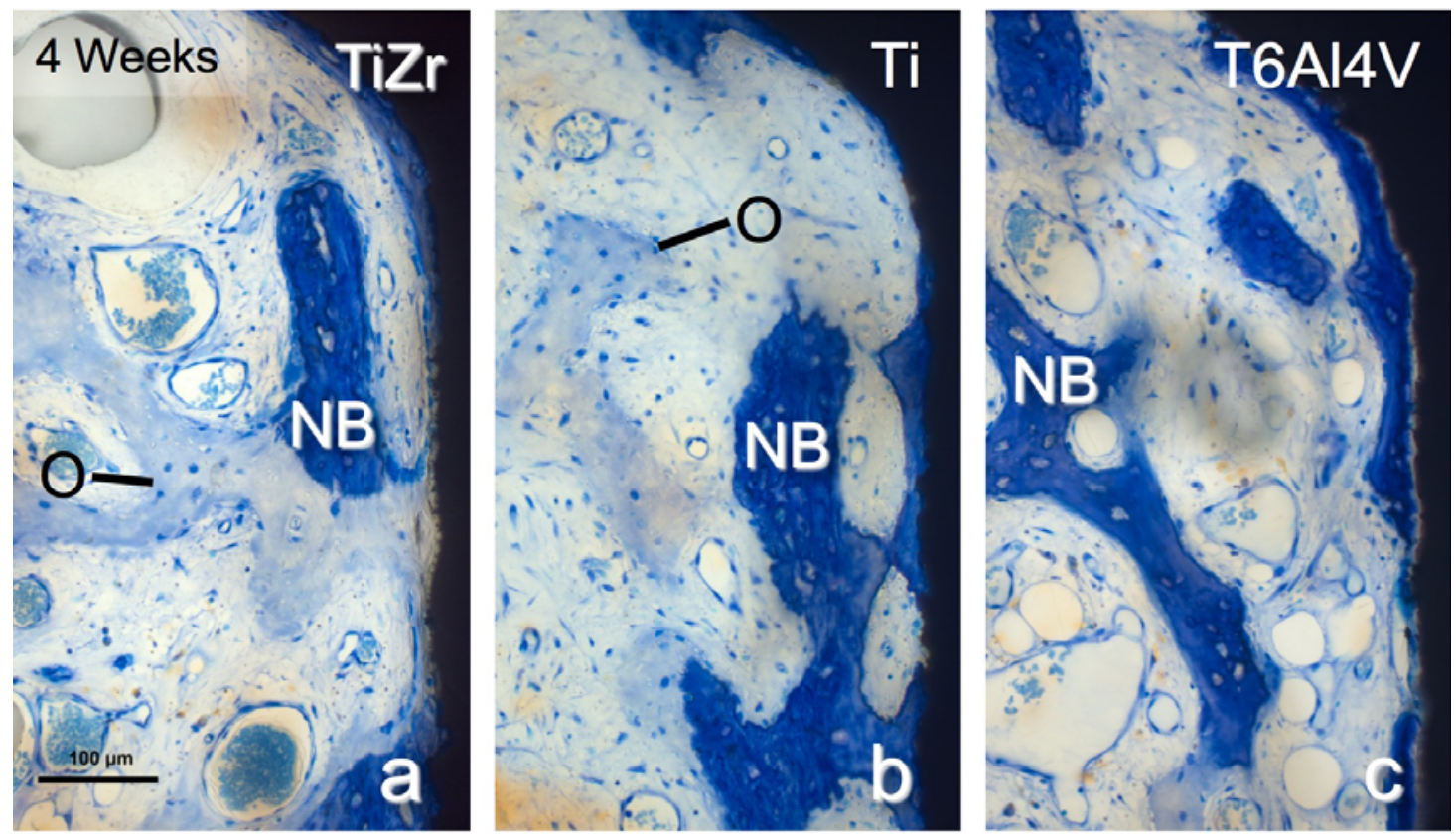

Fig. 7. Detailed histological views of the TiZr (a), cpTi (b) and Ti6Al4V (c) implant materials. After 4 weeks, the new bone consists of osteoid $(\mathrm{O})$ and mineralised bone matrix $(\mathrm{NB})$. A layer of new mineralised bone covers the implant surface.
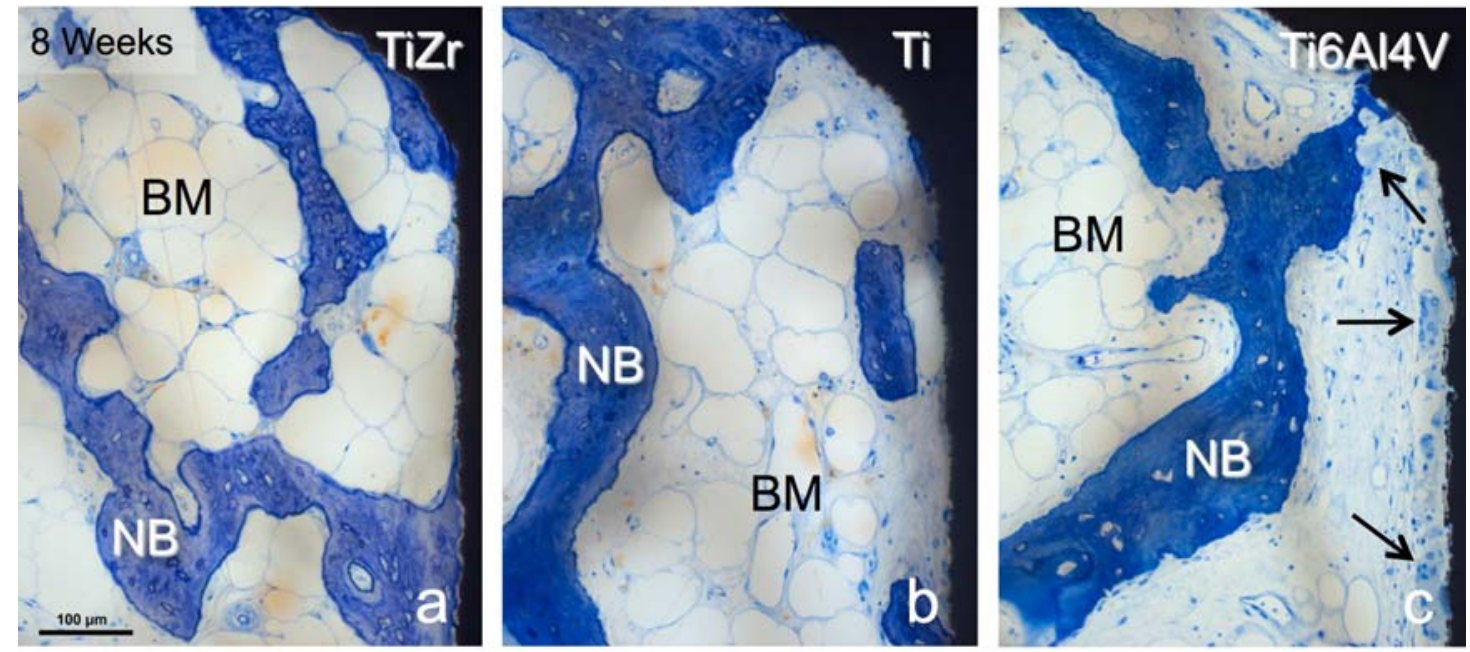

Fig. 8. Detailed histological views of TiZr (a), cpTi (b) and Ti6Al4V (c) implant materials at 8 weeks. Both the newly formed bone matrix (NB) and bone marrow (BM) are mature. Note the presence of fatty marrow tissue. Numerous MNGCs (arrows) line the Ti6Al4V implants, the bone-to-implant contact is very low, and the scalloped bone surface indicates resorptive activity.

(Sista et al., 2011). Minor differences in surface roughness $(\mathrm{Ra}<0.50 \mu \mathrm{m})$ may directly regulate the percentage of cell adhesion and cytoskeletal organisation (Castellani et al., 1999). The percentage of initial attachment and proliferation of osteogenic cells was higher for TiZr alloy than for cpTi, with similar cell viability and spreading on both surfaces (Sista et al., 2011). Further in vitro data indicate that alkali and heat pre-treatment of $\mathrm{cpTi}, \mathrm{Zr}$ and TiZr forms an apatite coating with a nanocrystalline microstructure, and that the speed of apatite formation appears to be related to the roughness value (Chen et al., 2008). Following immersion in simulated body fluid, a uniform and continuous apatite layer was formed on cpTi at 2 weeks and on $\mathrm{Zr}$ and TiZr at 3 weeks. This may be an explanation for the slight delay in bone apposition onto TiZr (SLActive) as opposed to cpTi (SLActive) implants, as observed in the present and in another study (Thoma et al., 2011).

In the present study, rather similar values for BIC were found between TiZr (SLActive) and Ti (SLActive) implants at 4 and 8 weeks. The BIC value at 4 weeks for TiZr (SLActive) implants is comparable with that from another study in which the same implant groove model was used in miniature pigs (Gottlow et al., 2010). The BIC values for TiZr (SLActive) and cpTi (SLActive) implants in the present study at 4 and 8 weeks were significantly 

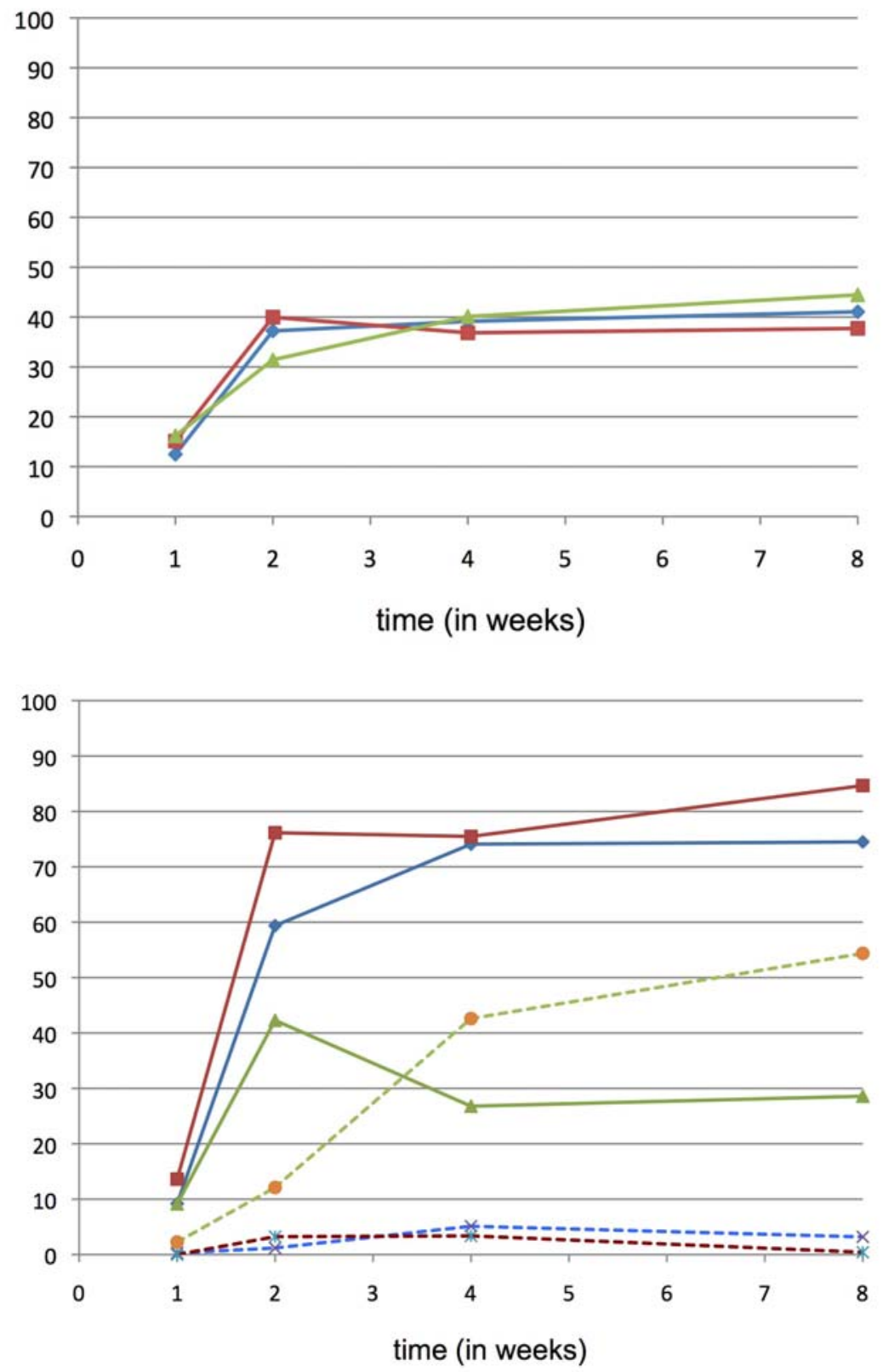

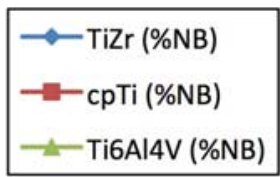

Fig. 9. Histogram illustrating the increase in area fraction of total new bone (osteoid and mineralised bone matrix) $(\% \mathrm{NB})$ over time within the implant grooves of the three implant materials.

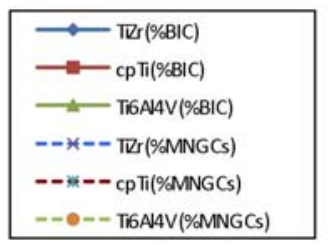

Fig. 10. Histogram illustrating the effect of the implant materials on the percentage of bone-toimplant contact $(\% \mathrm{BIC})$ and the percentage of implant surface along the grooves covered with MNGCs (\%MNGCs) over time. higher than those for Ti6Al4V implants. In other studies, a difference in BIC between Ti6Al4V and cpTi implants was also observed but did not reach statistical significance (Han et al., 1998; Johansson et al., 1998). However, in the study by Han et al. (1998) blasting was performed with $\mathrm{TiO}_{2}$ particles with mean sizes of $25 \mu \mathrm{m}$ in one group and $75 \mu \mathrm{m}$ in another group, while the implants used by Johansson et al. (1998) were machined. In contrast, blasting with $\mathrm{Al}_{2} \mathrm{O}_{3}$ and acid-washing with $65 \% \mathrm{HNO}_{3}$ was used in the present study. Thus, these studies do not allow a direct comparison. Although the blasting material $\mathrm{Al}_{2} \mathrm{O}_{3}$ is often embedded into the implant surface and may thus interfere with the osseointegration process, Le Guéhennec et al. (2007) and Wennerberg et al. (1996) could not find statistically significant differences in BIC values for cpTi implants blasted with $\mathrm{Al}_{2} \mathrm{O}_{3}$ or with $\mathrm{TiO}_{2}$ particles of the same size.

Because of the biphasic nature of Ti6Al4V, sandblasting and acid-etching is typically not an appropriate treatment for $\alpha$ - $\beta$-alloys. The exposure of Ti6Al4V to the same acid-etching (mixture of $\mathrm{HCl}$ and $\mathrm{H}_{2} \mathrm{SO}_{4}$ ) as compared to TiZr (SLActive) and cpTi (SLActive) leads to an enrichment of the Vanadium-rich $\beta$-phase on the surface. Hence, sandblasting and acid-washing, which represents a much less aggressive surface treatment, was used in the present study for Ti6Al4V implant materials and resulted in a different surface topography (Fig. 3c). There are also conditions that preferentially etch the $\beta$-rich phase (e.g. with $\mathrm{H}_{2} \mathrm{O}_{2} / \mathrm{H}_{2} \mathrm{SO}_{4}$ ) (Variola et al., 2008).

In the present study, numerous MNGCs were predominantly found on Ti6Al4V surfaces after 2, 4 and 8 weeks (Fig. 10). In previous reports, similar observations were made in vitro with monocytes exposed to severed Ti6Al4V particles from retrieved orthopaedic implants (Bainbridge et al., 2001) and in vivo on implant surfaces made of Ti6Al4V and cpTi (Han et al., 1998; Johansson et al., 1998). These authors attributed the presence of MNGCs to the occurrence of small free metal particles 
(Han et al., 1998) or the release of metal ions (Johansson et al., 1998). However, in the present study no free metal particles adjacent to the surface of any implant material were found. The presence of MNGCs obviously lowered the osseointegration values of Ti6Al4V implants. However, the low short-term biocompatibility found in the present study for Ti6Al4V implants differs from other studies where Ti6Al4 after sandblasting with aluminium oxide and nitric acid passivation was neither cytotoxic nor genotoxic (Velasco-Ortega et al., 2010). In another study using the dorsal skinfold chamber model in hamsters a slight increase in leukocyte recruitment and a more sluggish recuperation of inflammatory parameters was detected for Ti6Al4V when compared with cpTi (Pennekamp et al., 2006). Compared with stainless steel, the overall inflammatory response to Ti6Al4V was very similar (Ryhänen et al., 1998; Kapanen et al., 2001). Moreover, Ti6Al4V is considered as the material of choice for cementless implant materials in orthopaedics (Head et al., 1995) and successful clinical results were reported for Ti6Al4V dental implants that were machined and acid etched (De Leonardis et al., 1999) and sand-blasted and acid-etched (Bratu et al., 2009). Taken together, it is clear that the surface treatment of metal implants is very critical for the osseointegration process (Le Guéhennec et al., 2007; Wennerberg and Albrektsson, 2010). One plausible explanation for the low BIC and high surface coverage with MNGCs in the present study may be that sandblasting with $\mathrm{Al}_{2} \mathrm{O}_{3}$ followed by acid-washing with $65 \% \mathrm{HNO}_{3}$ created unfavourable material surface properties. Whether particle or ion release is also involved requires further studies. Furthermore, the small sample size and the explorative nature of the present study could be another confounding factor.

In conclusion, the chemically modified $\mathrm{TiZr}$ (SLActive) implant surface seems to have a similar potential for clinical applications as the clinically proven cpTi surface (SLActive). Based on the favourable mechanical properties and the fast osseointegration observed, the use of diameterreduced TiZr implants in more challenging clinical situations should be further examined in long-term clinical studies.

\section{Acknowledgments}

The authors wish to thank the staff at the Surgical Research Unit ESI and Clinic for Large Animals for excellent handling of the animals, Ms. Claudia Moser for her professional help during surgical procedures, Mr. David Reist for the histologic preparation of the specimens, Ms. Silvia Owusu for performing the histomorphometric analysis and Mr. Walter Bürgin for performing the statistical analysis. The study was funded by ITI Foundation for the Promotion of Implantology, Basel, Switzerland (Grant Nr. 665-2009).

\section{References}

Al-Nawas B, Brägger U, Meijer HJ, Naert I, Persson R, Perucchi A, Quirynen M, Raghoebar GM, Reichert TE, Romeo E, Santing HJ, Schimmel M, Storelli S,
Bruggenkate CT, Vandekerckhove B, Wagner W, Wismeijer D, Müller F (2011) A double-blind randomized controlled trial (RCT) of titanium-13zirconium versus titanium grade IV small-diameter bone level implants in edentulous mandibles - Results from a 1-year observation period. Clin Implant Dent Relat Res, in press (doi:10.1111/j.17088208.2010.00324.x).

Bainbridge JA, Revell PA, Al-Saffar N (2001) Costimulatory molecule expression following exposure to orthopaedic implants wear debris. J Biomed Mater Res 54: 328-334.

Barter S, Stone P, Bragger U (2011) A pilot study to evaluate the success and survival rate of titaniumzirconium implants in partially edentulous patients: results after 24 months of follow-up. Clin Oral Implants Res, in press (doi:10.1111/j.1600-0501.2011.02231.x).

Bauer J, Cella S, Pinto MM, Filho LE, Reis A, Loguercio AD (2009) Effect of argon purity on mechanical properties, microstructure and fracture mode of commercially pure (cp) Ti and Ti-6Al-4V alloys for ceramometal dental prostheses. Biomed Mater 4: 065002.

Bernhard N, Berner S, de Wild M, Wieland M (2009) The binary TiZr alloy - a new developed Ti alloy for use in dental implants. Forum Implantologicum 5: 30-39.

Bratu EA, Tandlich M, Shapira L (2009) A rough surface implant neck with microthreads reduces the amount of marginal bone loss: a prospective clinical study. Clin Oral Implants Res 20: 827-832.

Brunner E, Domhof S, Langer F (2002) Nonparametric analysis of longitudinal data in factorial experiments, John Wiley \& Sons, Inc., New York, pp 130-144.

Buser D, Schenk RK, Steinemann S, Fiorellini JP, Fox $\mathrm{CH}$, Stich H (1991) Influence of surface characteristics on bone integration of titanium implants. A histomorphometric study in miniature pigs. J Biomed Mater Res 25: 889-902.

Buser D, Nydegger T, Hirt HP, Cochran DL, Nolte LP (1998) Removal torque values of titanium implants in the maxilla of miniature pigs. Int J Oral Maxillofac Implants 13: 611-619.

Buser D, Broggini N, Wieland M, Schenk RK, Denzer AJ, Cochran DL, Hoffmann B, Lussi A, Steinemann SG (2004) Enhanced bone apposition to a chemically modified SLA titanium surface. J Dent Res 83: 529-533.

Castellani R, de Ruijter A, Renggli H, Jansen J (1999) Response of rat bone marrow cells to differently roughened titanium discs. Clin Oral Implants Res 10: 369-378.

Chen X, Nouri A, Li Y, Lin J, Hodgson PD, Wen C (2008) Effect of surface roughness of Ti, Zr, and TiZr on apatite precipitation from simulated body fluid. Biotechnol Bioeng 101: 378-387.

Chiapasco M, Casentini P, Zaniboni M, Corsi E, Anello $\mathrm{T}$ (2011). Titanium-zirconium alloy narrow-diameter implants (Straumann Roxolid) for the rehabilitation of horizontally deficient edentulous ridges: prospective study on 18 consecutive patients. Clin Oral Implants Res, in press (doi:10.1111/j.1600-0501.2011.02296.x).

Cochran DL, Schenk RK, Lussi A, Higginbottom FL, Buser D (1998) Bone response to unloaded and loaded titanium implants with a sandblasted and acid-etched surface: a histometric study in the canine mandible. $\mathrm{J}$ Biomed Mater Res 40: 1-11. 
De Leonardis D, Garg AK, Pecora GE (1999) Osseointegration of rough acid-etched titanium implants: 5-year follow-up of 100 minimatic implants. Int J Oral Maxillofac Implants 14: 384-391.

Germanier Y, Tosatti S, Broggini N, Textor M, Buser D (2006) Enhanced bone apposition around biofunctionalized sandblasted and acid-etched titanium implant surfaces. A histomorphometric study in miniature pigs. Clin Oral Implants Res 17: 251-257.

Gotfredsen K, Berglundh T, Lindhe J (2000) Anchorage of titanium implants with different surface characteristics: an experimental study in rabbits. Clin Implant Dent Relat Res 2: 120-128.

Gottlow J, Dard M, Kjellson F, Obrecht M, Sennerby L (2010) Evaluation of a new titanium-zirconium dental implant: A biomechanical and histological comparative sudy in the mini pig. Clin Implant Dent Relat Res, in press (doi:10.1111/j.1708-8208.2010.00289.x).

Han CH, Johansson CB, Wennerberg A, Albrektsson $\mathrm{T}$ (1998) Quantitative and qualitative investigations of surface enlarged titanium and titanium alloy implants. Clin Oral Implants Res 9: 1-10.

Head WC, Bauk DJ, Emerson RH Jr (1995) Titanium as the material of choice for cementless femoral components in total hip arthroplasty. Clin Orthop Relat Res 311: 85-90.

Hinrichs F, Kuhl M, Boudriot U, Griss P (2003) A comparative clinical outcome evaluation of smooth (10-13 year results) versus rough surface finish (5-8 year results) in an otherwise identically designed cemented titanium alloy stem. Arch Orthop Trauma Surg 123: 268-272.

Ho WF, Chen WK, Wu SC, Hsu HC (2008) Structure, mechanical properties, and grindability of dental $\mathrm{Ti}-\mathrm{Zr}$ alloys. J Mater Sci Mater Med 19: 3179-3186.

Johansson CB, Lausmaa J, Röstlund T, Thomsen P (1993) Commercially pure titanium and Ti6Al4V implants with and without nitrogen-ion implantation: surface characterization and quantitative studies in rabbit cortical bone. J Mat Sci: Mater Med 4: 132-141.

Johansson CB, Han CH, Wennerberg A, Albrektsson $\mathrm{T}$ (1998) A quantitative comparison of machined commercially pure titanium and titanium-aluminumvanadium implants in rabbit bone. Int $\mathrm{J}$ Oral Maxillofac Implants 13: 315-321.

Johnsen SP, Sorensen HT, Lucht U, Soballe K, Overgaard S, Pedersen AB (2006) Patient-related predictors of implant failure after primary total hip replacement in the initial, short- and long-terms. A nationwide Danish follow-up study including 36,984 patients. J Bone Joint Surg Br 88: 1303-1308.

Kapanen A, Ryhänen J, Danilov A, Tuukkanen J (2001) Effect of nickel-titanium shape memory alloy on bone formation. Biomaterials 22: 2475-2480.

Kobayashi E, Matsumoto S, Doi H, Yoneyama T, Hamanaka H (1995) Mechanical properties of the binary titanium-zirconium alloys and their potential for biomedical materials. J Biomed Mater Res 29: 943-950.

Lang NP, Salvi GE, Huynh-Ba G, Ivanovski S, Donos N, Bosshardt DD (2011) Early osseointegration to hydrophillic and hydrophobic implant surfaces inhumans. Clin Oral Implants Res 22: 349-356.
Le Guehénnec L, Soueidan A, Layrolle P, Amouriq Y (2007) Surface treatments of titanium dental implants for rapid osseointegration. Dent Mater 23: 844-854.

Malmqvist JP, Sennerby L (1990) Clinical report on the success of 47 consecutively placed Core-Vent implants followed from 3 months to 4 years. Int J Oral Maxillofac Implants 5: 53-60.

Pennekamp PH, Gessmann J, Diedrich O, Burian B, Wimmer MA, Frauchiger VM, Kraft CN (2006) Shortterm microvascular response of striated muscle to cp-Ti, Ti-6Al-4V, and Ti-6Al-7Nb. J Orthoped Res 24: 531-540.

Rangert B, Krogh PH, Langer B, Van Roekel N (1995) Bending overload and implant fracture: a retrospective analysis. Int J Oral Maxillofac Implants 10: 326-334.

Ryhänen J, Kallionen M, Tuukkanen J, Junila J, Niemelä E, Sandvik P, Serlo W (1998) In vivo biocompatibility evaluation of nickel-titanium shape memory metal alloy: Muscle and perineural tissue responses and encapsule membrane thickness. J Biomed Mater Res 41: 481-488.

Schenk RK, Olah AJ, Hermann W (1984) Preparation of calcified tissues for light microscopy. In: Methods of calcified tissue preparation (Dickson GR, ed), Elsevier Science Publishers, Amsterdam, pp 1-56.

Schwarz F, Wieland M, Schwartz Z, Zhao G, Rupp F, Geis-Gerstorfer J, Schedle A, Broggini N, Bornstein MM, Buser D, Ferguson SJ, Becker J, Boyan BD, Cochran DL (2009) Potential of chemically modified hydrophilic surface characteristics to support tissue integration of titanium dental implants. J Biomed Mater Res B Appl Biomater 88: 544-557.

Sista S, Wen C, Hodgson PD, Pande G (2011) The influence of surface energy of titanium-zirconium alloy on osteoblast cell functions in vitro. J Biomed Mater Res A 97A: 27-36.

Steinemann SG, Simpson J (2004) Osteophilic implants. USPTO. USA: Institut Straumann AG, Switzerland.

Sul YT, Johansson CB, Jeong Y, Wennerberg A, Albrektsson T (2002) Resonance frequency and removal torque analysis of implants with turned and anodized surface oxides. Clin Oral Implants Res 13: 252-259.

Textor M, Sittig C, Frauchiger V, Tosatti S, Brunette DM (2001) Properties and biological significance of natural oxide films on titanium and its alloys. In: Titanium in medicine (Brunette DM, Tengvall P, Textor M, Thomsen P, eds), Springer, Berlin, pp 171-230.

Thoma DS, Jones AA, Dard M, Grize L, Obrecht M, Cochran DL (2011) Tissue integration of a new titaniumzirconium dental implant: A comparative histologic and radiographic study in the canine. J Periodontol 82: 14531461.

Variola F, Yi JH, Richert L, Wuest JD, Rosei F, Nanci A (2008) Tailoring the surface properties of Ti6Al4V by controlled chemical oxidation. Biomaterials 29: 12851298.

Velasco-Ortega E, Jos A, Cameán AM, Pato-Maurelo J, Segura-Egea JJ (2010) In vitro evaluation of cytotoxicity and genotoxicity of a commercial titanium alloy for dental implantology. Mutat Res 702: 17-23.

Weibel ER (1979) Stereological Methods. Vol. I: Practical Methods for Biological Morphometry. Academic Press, New York. 
Wennerberg A, Albrektsson T, Johansson C, Andersson B (1996) Experimental study of turned and grit-blasted screw-shaped implants with special emphasis on effects of blasting material and surface topography. Biomaterials 17: $15-22$.

Wennerberg A, Albrektsson T (2010) On implant surfaces: a review of current knowledge and opinions. Int J Oral Maxillofac Implants 25: 63-74.

Willert HG, Broback LG, Buchhorn GH, Jensen PH, Koster G, Lang I, Ochsner P, Schenk R (1996). Crevice corrosion of cemented titanium alloy stems in total hip replacements. Clin Orthop Relat Res 333: 51-75.

Zinsli B, Sagesser T, Mericske E, Mericske-Stern R (2004) Clinical evaluation of small-diameter ITI implants: a prospective study. Int J Oral Maxillofac Implants 19: 92-99.

\section{Discussion with Reviewers}

H. Plenk: Morphometry of bone-to-implant interfaces by grid counting: Of course, grids with appropriate line distances, corresponding to the microscopic magnification as well as the orientation and distances of the bone structures have their value. However, particularly for the initial and spotty new bone deposition on implant surfaces, even an experienced observer will not perform properly, and may even be biased, while computerised evaluation of digital images is clearly superior.

Authors: We agree that computer-supported evaluation of digital images has undoubtedly its place in histometric evaluation of osseointegration. In recent years, we have compared classical grid counting technique with length or distance measurements on the computer screen. We would love to use such a computer-assisted program to measure the BIC. This is in most cases certainly a very appropriate technique, in particular for interface analysis of healed sites. However, in the case of bone matrix deposition onto an implant surface at a very early stage of healing, when tiny amounts of bone matrix are being deposited, we are still thoroughly convinced that the computer-assisted method is inferior to the grid counting technique and this for the following reasons: The grid counting technique can be performed directly in the microscope with the highest possible magnification and resolution. This live image allows subtle focusing so that the interface between the implant and bone can always be optimally seen and therefore appropriately analysed. The disadvantage of this technique is that in case of very low BIC values, the given distance between adjacent lines in the grid may lead to inaccurate values. In contrast, length/distance measurements performed on the computer monitor do not have this disadvantage. However, the distinction between osteoid, mineralised new bone, bone debris particles (i.e., old bone), and soft tissue in contact with the implant surface has limitations due to a lower resolution and varying depths of focus. This is particularly the case at a very early stage of bone matrix deposition. In conclusion, we are thoroughly convinced that direct observation in the light microscope and the use of the grid counting technique is advantageous when it comes to investigating very initial bone matrix deposition onto metal or ceramic implants.

Reviewer II: What were the reasons for using Ti6Al4V as second control group?

Authors: This alloy has been chosen for two reasons: (a) it is a well-established Ti-alloy in orthopaedic implantology and (b) it has an increased mechanical strength when compared to cpTi, and similar mechanical qualities as the TiZr-alloy. Thus, it could as well be an alternative for small diameter dental implants.

Reviewer III: The ground sections were as thick as 80 $\mu \mathrm{m}$, which makes cellular details difficult to analyse. Please comment.

Authors: Our ground sections are indeed $80 \mu \mathrm{m}$ in thickness. Most other histology laboratories use the Exakt System with a diamond-coated band saw where the ground sections are glued on transparent slides and ground down to 20-30 $\mu \mathrm{m}$. Developed by Prof. Robert Schenk, one of the pioneers in the field of osteosynthesis research, in our laboratory a low-speed Leco sawing machine with diamond-coated metal disks (wafers) is used, and instead of transparent mounting slides we use opalescent 1-2 $\mathrm{mm}$ thick plastic plates to support the ground sections, combined with a surface stain technology. At first sight, this may violate the rules of correct microscopic illumination, but in combination with the thick, surface stained sections it has a tremendous advantage that clearly outweighs the drawbacks resulting from neglecting the optical laws. The light passing through the opalescent slide and the surfacestained section enable inspection of the very surface of the ground section with high resolution irrespective of section thickness. We could even use $200 \mu \mathrm{m}$ thick sections with this technique without loss of resolution. Thus, there is actually no advantage of using thinner ground sections and there is no overestimation of the true bone-to-implant contact. Both qualitative and quantitative microscopy of our sample preparation technique are at least as good as with other techniques that use thinner sections.

H. Plenk: Toluidine blue is not a "metachromatic" stain, but stains cells and tissue ECM in different shades of "orthochromatic" blue(!), while only acidic proteoglycans, such as in the cartilage ECM, exhibit a metachromatic staining reaction in violet to red. This is due to the physicochemical position of the reactive groups in transmitted light. To solve the problem of distinction of osteoid from mineralised bone, the application of a counterstain, such as with Eosin in the Giemsa-solution, or with basic Fuchsin which Schenk used very successfully in many studies, would have allowed a clear differentiation of osteoid from mineralised early woven and mature lamellar bone.

Authors: When we were referring to the "metachromatic" properties of toluidine blue, we had, of course, the metachromatic staining properties of cartilage in mind. We fully agree that for the majority of tissues, toluidine blue behaves like an "orthochromatic" dye. We indeed apply the double staining technique of Prof. Schenk with toluidine blue and basic fuchsin in many ground 
sections. However, we only apply this staining technique for the sake of producing beautiful images with a nice contrast between soft and hard tissues. When it comes to histomorphometric measurements, and particularly when osteoid needs to be distinguished from mineralised bone matrix, our experience is that the toluidine blue according to the method of McNeal is clearly superior to the abovementioned double staining. Therefore, we see no reason to switch to the double staining technique.

Reviewer IV: The authors define osteoid as part of the bone tissue. Wouldn`t it be more fitting to restrict this classification to mineralised bone tissue alone and see osteoid as a parameter describing the formation dynamics? Authors: If a material is more osteoconductive than another material, a difference in the amount of bone matrix deposited onto the material is expected to take place during the very early phases of healing. Indeed, several studies have shown that this is the case and that at later healing periods no significant differences exist anymore. Osteoid was determined in both of these two situations. Also osteoid at the leading (building) front of woven bone formation was considered, although not as clearly visible as in the case of later stages of bone apposition. Particular attention was paid to distinguish between tissue that develops into woven bone and non-osteogenic soft tissue. Criteria to distinguish between these two situations include: size and shape of cells, structure and density of the collagenous extracellular matrix, and number and distribution of blood vessels.

Reviewer II: It is doubtful that the general public is aware of the existence of osteoid laid down for woven bone production. As the larger part of your measured osteoid appears to be of that type, again for the sake of reproducibility, the readers should be made aware of this fact. If somebody would try to reproduce the study and only measured "lamellar bone osteoid" the results would be completely different.

Authors: We agree that the "osteoid" of woven bone is not comparable to the osteoid of parallel-fibered or lamellar bone. Since this is a critical aspect and not many people are aware of this difference we have added the following sentence in the M\&M section: "Osteoid is the organic nonmineralised matrix of bone consisting of collagen and noncollagenous proteins." Osteoid in lamellar bone forms a thin matrix seam that is homogeneously eosinophilic and interposed between osteoblasts and mineralised bone matrix. Such a clear-cut distinction between mineralised bone matrix and osteoid cannot be made for woven bone. However, also during woven bone formation an equivalent to osteoid exists. Due to the structural nature of woven bone, the osteoid consists of thick randomly distributed collagen fibres, which intermingle with nearby osteoblasts. Importantly, the osteoid of woven bone can clearly be distinguished from the soft tissue, rich in blood vessels, that fills the more central portion of neighbouring struts of woven bone.

Reviewer I: Why do the dimensions of the "chamber" of the TiZr-implant at 1 week in Fig. 3 look so different from all other chambers, if the images have the same magnification? Were the grooves (or the "circular rings") on the cylindrical implants not all of the same size?

Authors: It is impossible that all grooves look the same. Not every middle section is precisely going through the real centre of an implant. Sometimes, a section is right in the centre, sometimes slightly off-centre. Therefore, the depths of the grooves vary.

Reviewer I: No TRAP staining was done. Please comment. Authors: TRAP is believed to be specific for osteoclasts/ odontoclasts. Osteoclasts are large, usually multinucleated cells with a ruffled border and a sealing zone, expressing a variety of molecules including TRAP, RANK, c-Fms, VNR, CTR, CD68 etc. In the present study, we are dealing with large, multinucleated cells adhering on metal surfaces. These cells cannot be regarded as osteoclasts. They rather are foreign body cells. Thus, the use of a cell marker for foreign body cells would be much more appropriate. Unfortunately, the application of cell markers in tissues embedded in MMA is very restricted because of masking and antigen destruction due to heat production during polymerisation. Based on the striking observation of many MNGCs on the TAV implants treated with $\mathrm{HCl}$ and $\mathrm{H}_{2} \mathrm{SO}_{4}$ after sandblasting, future investigations may use other models and techniques to detect markers associated with MNGCs.

Reviewer II: The formation of bone in cancellous areas is certainly faster than in cortical ones. But is the total and relative amount of newly formed bone tissue not eventually higher in cortical regions? That at least is my experience. Please comment!

Authors: Your are right, once bone formation is established and remodelling sets in, it can be anticipated that the "bone density" is higher in cortical bone than in cancellous bone, provided that compact bone persists at such a site.

Reviewer II: How far is the minipig model transferable to the human situation?

Authors: Within a specific field of research, no single animal model might be ideal to answer all purposes. Minipigs are large and skeletally mature animals that mimic the bone biology of humans better than rodents, which have a much faster metabolism and remodelling rate and are thus less suitable to represent a typical clinical situation. Minipigs are reported as a suitable model for a variety of research topics including bone fractures (Pearce et al., 2007, additional reference), bone grafting materials (Jensen et al., 2011, additional reference) and dental implants (Buser et al., 2004, text reference). Furthermore, a recent study in humans (Lang et al., 2011, text reference) showed that the same difference between cpTi implants with SLA and SLActive surfaces was found as in minipigs (Buser et al., 2004, text reference). Thus, the minipig for bone research appears to be close to the human situation and avoids the use of non-human primates, which are always associated with ethical concerns an substantially elevated research costs (Muschler et al., 2010, additional reference). 
Reviewer III: The TiAl4V surfaces were not chemicallyactivated (SLActive). Could authors comment on the effect of such activation on the overall performance of the surfaces?

Authors: The main differences of the chemically modified SLA surface (SLActive) compared to the non-activated SLA are the following: The activation leads to a low level of carbon contamination and thus to a hydrophilic surface with a high surface energy, whereas non-activated surfaces present a higher level of carbon contamination resulting in hydrophobic surfaces (low surface energy). It is believed that the hydrophilicity is highly beneficial for the formation of the fibrin network and for the stabilisation of the blood clot. Therefore, the modified surface is beneficial at an early stage of the healing phase and accelerates the whole healing process (Hong et al., 2011, additional reference). Furthermore, in a similar implant model as in the present study, significantly enhanced bone apposition was found on Ti implants with SLActive treatment compared to Ti implants with SLA treatment (Buser et al., 2004, text reference). To the best of our knowledge, we do not know what the effect of such an implant surface modification may be on a sandblasted and $\mathrm{HCl}$ and $\mathrm{H}_{2} \mathrm{SO}_{4}$ treated Ti6Al4V material.

Reviewer III: Please discuss the differences between $\mathrm{TiO}_{2}$ and $\mathrm{Al}_{2} \mathrm{O}_{3}$ used as blasting materials.

Authors: In addition to the potential risk of $\mathrm{Al}$ ion dissolution from the blasting material into the host tissue, the histomorphometrical analysis of implants blasted with $\mathrm{Al}_{2} \mathrm{O}$ and $\mathrm{TiO}_{2}$ particles of the same size demonstrated no significant differences (Wennerberg et al., 1996, text reference). However, a potential difference might be expected when sandblasting occurs on a different implant material, since the release of Al ions from Ti6Al4V implants blasted with $\mathrm{Al}_{2} \mathrm{O}_{3}$ particles coincided with lower values of removal torque and bone-to-implant contact in comparison with cpTi implants (Johansson et al., 1992, additional reference). It is also possible, that the $\mathrm{Al}_{2} \mathrm{O}_{3}$ particles are not more toxic than $\mathrm{TiO}_{2}$ particles. Actually, $\mathrm{TiO}_{2}$ particles might even provoke a significantly higher TNF $\alpha$ response than $\mathrm{Al}_{2} \mathrm{O}_{3}$ particles of the same size (Sterner et al., 2004, additional reference). The inhibition of cell proliferation by $\mathrm{Al}_{2} \mathrm{O}_{3}$ and $\mathrm{TiO}_{2}$ particles is very low, which makes difficult to detect small differences in their toxic behaviour (Yamamoto et al., 2004, additional reference). The different tissue responses to the two types of particles might thus be explained by geometrical factors, i.e. their size, shape and structure. As previously reported, the attenuation of osteoblast function depends on the size of Ti particles; different mechanism may be elicited by Ti particles of different sizes (Choi et al., 2005, additional reference). Considering cell cytotoxicity of $\mathrm{TiO}_{2}$ particles in different shapes, the dendritic particles had the strongest effect followed by spindle and spherical shapes (Yamamoto et al., 2004, additional reference). These results suggest that the number of sharp edges is important for cytotoxicity, since the fibrous shape was more cytotoxic than the spherical shape.
Reviewer I: If future researches are in the horizon, are authors planning to use comprehensive, possibly nondestructive methods to quantitate and compare bone formation at the implant interface?

Authors: In order to evaluate the rate of osseointegration over time for new implant materials/surface treatments, we will continue to use morphometric measurements performed in ground sections and this for the following two reasons: (1) This reliable technique allows comparison with data from other studies where the same technique was applied, and (2) Although for example micro-CT is a non-destructive method that allows quantification of bone volume and other parameters with nowadays also high resolution, the vicinity to a metal implant generates aberrations. The bone-to-implant contact measurements have to be performed at the metal-bone interface. The bone at this interface is extremely thin, particularly after 1 week of healing, and can therefore not accurately be determined by any radiographic technique available today.

\section{Additional References}

Choi MG, Koh HS, Kluess D, O’Connor D, Mathur A, Truskey GA, Rubin J, Zhou DX, Sung KL (2005) Effects of titanium particle size on osteoblast functions in vitro and in vivo. Proc Natl Acad Sci USA 102: 4578-4583.

Hong J, Kurt S, Thor A (2011) A hydrophilic dental implant surface exhibits thrombogenic properties in vitro. Clin Implant Dent Relat Res, in press. doi 10.1111/j.17088208.2011.00362.x.

Jensen SS, Chen B, Bornstein MM, Bosshardt DD, Buser D (2011) Effect of enamel matrix derivate and parathyroid hormone on bone formation in standardized osseous defects: an experimental study in minipigs. J Periodontol 82: 1197-1205.

Johansson C, Albrektsson T, Thomsen P, Sennerby L, Lodding A, Odelius H (1992) Tissue reactions to titanium6aluminium-4vanadium alloy. Eur J Exp Musculoskel Res 1: 161-169.

Muschler GF, Raut VP, Patterson TE, Wenke JC, Hollinger JO (2010) The design and use of animal models for translational research in bone tissue engineering and regenerative medicine. Tissue Eng Part B Rev 16: 123-145.

Pearce AI, Richards RG, Milz S, Schneider E, Pearce SG (2007) Animal models for implant biomaterial research in bone: a review. Eur Cell Mater 13: 1-10.

Sterner T, Schütze N, Saxler G, Jakob F, Rader CP (2004) Effects of clinically relevant alumina ceramic, zirconia ceramic and titanium particles of different sizes and concentrations on TNF-alpha release in a human macrophage cell line. Biomed Tech (Berl) 49: 340-344.

Wennerberg A, Albrektsson T, Johansson C, Andersson B (1996) Experimental study of turned and grit-blasted screw-shaped implants with special emphasis on effects of blasting material and surface topography. Biomaterials 17: 15-22.

Yamamoto A, Honma R, Sumita M, Hanawa T (2004) Cytotoxicity evaluation of ceramic particles of different sizes and shapes. J Biomed Mater Res A 68: 244-256. 